\title{
The Effects of Scarcity Message on Sales Promotions Based on Self-Monitoring Levels in T-Commerce
}

\author{
KwangSeok Han, Professor, Department of Advertising and Public Relations, 91, Daehakro Seobukgu \\ Cheonan, 3120 Korea, kshan@nsu.ac.kr \\ ${ }^{*}$ Corresponding author
}

\begin{abstract}
The purpose of this study was to empirically verify the effects of scarcity messages on sales promotions and purchase intentions of T-Commerce consumers, based on their self-monitoring levels. This experiment used factor design between subjects according to the scarcity type (quantity-limited vs. time-limited) and self-monitoring level (high-monitored vs. high-monitored) of the T-commerce sales promotion message and analysis was performed using the two-way MANOVA analysis. Two-way MANOVA analysis of T-commerce's scarcity message, self-monitoring, two independent variables, dependent promotional attitudes, and purchase intentions. The results of this study are as follows. First, consumers' attitudes toward sales promotions and purchase intentions in T-Commerce were found to be relatively positive with regard to limited-quantity and limited-time messages, with no major differences observed between the two types of messages. Second, T-Commerce consumers with high levels of selfmonitoring formed more positive attitudes toward sales promotions and has higher purchase intentions when limited-quantity messages were used, as compared to when limited-time messages were used. Third, a more positive attitude toward promotions and higher purchase intentions with limited-quantity messages are demonstrated by consumers with high levels of self-monitoring, rather than those with low levels. Consumers use T-Commerce while watching TV in the comfort of their homes. Therefore, a limitation of this study is that it was conducted in artificial settings.
\end{abstract}

Keywords:

Scarcity Message, Sales Promotion, T Commerce, Price Discount, Attitude, Purchase Intention Received: 08.12.2020 Accepted: 14.01.2021 Published: 06.02.2021

\section{INTRODUCTION}

Interactive digital TV broadcasting has led to the emergence of T-Commerce, which allows users to search for products and related information directly on TV, as well as to purchase these products. TCommerce, a compound term combining "TV" and "Commerce," is a "data broadcasting home shopping service" in which users can search for products on Internet TV or cable broadcasting using a TV remote control, select the desired products, and make purchases. It differs from TV home shopping, which is broadcast live and in which orders are placed through ARS or a dedicated mobile app. T-Commerce centers on recorded broadcasting, and a separate TV app is provided after a few seconds to allow viewers to place orders.

In contrast to the existing live home shopping broadcasts, in which the role of a show host is important, T-Commerce poses no limitations related to place or time, thereby enabling new imaging techniques or sales methods to be tried at any time. The effect of "scarcity messages"—which stimulate viewers' purchasing psychology and promote purchasing behavior-is particularly noteworthy. Scarcity messages - such as "Limited Sale of 100 Items" or "Limited Sale for 3 Days"-play a significant role in promoting purchases by highlighting the limited availability of products or services[1]. Such scarcity messages are frequently used along with "limited-quantity messages," which inform consumers about limited sale quantities, and "limited-time messages," which highlight the short sale period, thus stimulating consumers' desire to make purchases[2]. Prior studies have shown that limited-quantity messages, which generally imply competition with other consumers, have a relatively greater influence on consumers' purchase intention than limited-time messages[3]. However, there is a lack of studies that consider consumers' personal and situational variables to identify the differences between the effects of limited-quantity messages and limited-time messages. Therefore, it is necessary to focus on a variable known as "self-monitoring," which affects consumers' motivational factors. "Self-monitoring" refers to the extent to which an individual's behavior is affected by social circumstances[4]. It is a tendency of practicing self-observation, self-control, and self-management in various situations for determining 
whether one's expressive behavior is socially appropriate or not.

\section{Background and Hypothesis}

\subsection{T-Commerce}

T-Commerce refers to a service that enables commercial transactions, such as product information search, purchase, payment, etc., on a TV using a remote control. In T-Commerce, electronic commerce (ECommerce)-ordering products through the Internet-is conducted on a TV. Through the use of a remote control, users can not only search for product information but can also make purchases and payments immediately. In contrast to TV home shopping, in which the show host continuously provides shopping information through one-way communication to passive consumers, T-Commerce is characterized by twoway real-time communication and active participation of consumers. In addition, contrary to TV home shopping, in which users can view only live product information, consumers using T-Commerce are equipped with search and payment functions that enable users to browse a larger number of products and make purchases at any time due to the nature of digital TV-which "datafiles" and provides product information. Therefore, consumers can enjoy shopping in a more active manner. In addition, users can enjoy more personalized and customized TV shopping as the products that consumers frequently search for and their purchases are accumulated over time and used as data.

There has been scant prior research on T-Commerce. Among these, a study found that consumers make numerous impromptu visits on TV home shopping, whereas Internet shopping tends to attract more habitual and purposeful visits. T-commerce fairs somewhere between TV home shopping and Internet shopping in terms of the number of impromptu, habitual, and purposeful visits, which appear relatively evenly. In addition, a study on the factors determining the purchases and continuous use of TV home shopping, Internet shopping, and T-Commerce found that affordability and seller trust are the most important factors for all shopping services (i.e., TV home shopping, Internet shopping, and TCommerce)[5]. In a study on the effects of online grocery shopping experiences on grocery shopping intention in T-Commerce, Lee et al. (2015) found that the group that had prior online grocery shopping experiences exhibited a higher intention to purchase grocery via T-Commerce compared to the group without prior online grocery shopping experience[6]. Nonetheless, research on T-Commerce is lacking because the service is still in its beginning stage. In Brazil, however, research has been conducted to develop efficient TV home shopping applications that are tailored to consumers and their TV usage patterns[7].

\subsection{Scarcity Message}

Scarcity messages refer to a message appealing method to promote consumers' purchase decisionmaking by inducing or increasing the psychological pressure on consumers by informing them that the availability of a particular product is limited[8]. Limited-quantity messages and limited-time messages are examples of scarcity messages analyzed in previous studies[9].

Limited-quantity messages refer to a promotion method frequently used in retail stores to inform consumers that the quantity of products for sale is limited. Similarly, limited-time messages are used to maximize the effects of "scarcity messages" by limiting the time available for ordering a product; in other words, limited-time messages limit the amount of time during which a product can be purchased.

Prior studies have demonstrated that limited-quantity messages, which imply competition between consumers, are more effective in increasing consumers' purchase intention than limited-time messages, which allow the consumer to purchase a product or service at any time within a given period[10,11, 12]. In other words, limited-quantity messages activate a feeling of potential loss in consumers-that they may be unable to purchase a product or service-as compared to limited-time messages. Therefore, the psychological value of limited-quantity message perceived by consumers is higher than that of limitedtime messages. However, there is a lack of research on how the scarcity message effect is influenced by certain situational and intrinsic variables for producing the "relative effect," and on comparisons between the two variables. To summarize, there is a need for examining the controlling effects of personal variables while studying the effects of scarcity messages.

\subsection{Self-Monitoring}

"Self-monitoring" refers to the tendency of observing, controlling, and managing one's behavior according to contextual cues for personal recognition in society[13]. In addition, self-monitoring 
highlights individuals' varying expressive behaviors for being recognized by others, depending on the situation. Therefore, the level of interest with which one looks to others varies depending on their level of self-monitoring, which plays an important role in understanding market behavior associated with "personal influence." Self-monitoring has also been frequently mentioned in studies on the extent to which an individual controls his or her behavior or self-expression in line with social cues.

People with high levels of self-monitoring have significant interest in whether their actions are appropriate for interpersonal relationships and social life, and are sensitive regarding whether their expressed behaviors and self-presentation will be accepted by others. In addition, situational cues are often used as verbal and non-verbal means of self-monitoring. On the other hand, people with low levels of self-monitoring tend to not pay attention to whether their self-presentation is socially appropriate, and lack the skills necessary to regulate their self-presentation. Therefore, their behaviors toward other individuals are characterized as consistent[14].

In general, people with high levels of self-monitoring are sensitive to trademarks and what they symbolize for them[15]. People with low levels of self-monitoring are more dependent on their own conclusions as they are greatly influenced by their inner cues, whereas people with high levels of selfmonitoring are less dependent on their own conclusions and strongly dependent on external contextual cues[16]. In their study of advertising effectiveness, Snyder and Attridge(1988) found that people with high levels of self-monitoring formed a positive attitude toward image-centered advertising, whereas those with low levels of self-monitoring had a positive attitude toward advertising related to a product's attributes[17].

With the above considerations, the following hypotheses are proposed for empirical verification:

H1: Consumers with high levels of self-monitoring will have a more positive attitude toward sales promotions using limited-quantity messages than toward those using limited-time messages.

H2: Consumers with high levels of self-monitoring will have more positive purchase intentions when limited-quantity messages are used than when limited-time messages are employed.

H3: Consumers with low levels of self-monitoring will have a more positive attitude toward sales promotions using limited-time messages than toward those using limited-quantity messages.

H4: Consumers with low levels of self-monitoring will have more positive purchase intentions when limited-time messages are used than when limited-quantity messages are employed.

H5: Limited-quantity messages will have a greater effect on consumer attitudes toward sales promotions and purchase intentions compared to limited-time messages.

\section{Research Method}

\subsection{Experimental Design}

This experiment used factor design between subjects according to the scarcity type (quantity-limited vs. time-limited) and self-monitoring level (high-monitored vs. high-monitored) of the T-commerce sales promotion message and analysis was performed using the two-way MANOVA analysis.

All of these experiments allowed subjects to actually manipulate the experimental stimuli while watching T-commerce videos through TV remote control in a certain experimental space. 73 subjects participated in the limited quantity message, 82 subjects participated in the limited time message, and a total of 155 subjects participated.

\subsection{Experimental Manipulation}

Pre-survey was conducted through targeted group interviews (FGI) with eight college students to select products or services to be tested in this study. The subjects selected a product called 'Boss IE2', which is a wireless Bluetooth headphone, in consideration of the products or services that reflect their lifestyle, which are not unfamiliar and frequently used.

By editing the actual T-Commerce screen, a Bluetooth headphone advertisement is inserted in the middle of the video screen and edited as a video explaining it. In order to stimulate the scarcity message, in the case of the quantity-limited message, the message of limited sales was presented to only 200 people on a first-come-first-served basis. Specifically, the limited-quantity messages consisted of limited edition messages such as 'Limited sales of 200 people on a first-come, first-served basis!' and 'Limited sales of 200 people. In addition, the time-limited messages consisted of the messages, 'Only for one day on December 4th,' and 'Only for one day, limited sales starting from midnight on the event start date.' In addition, in order to manipulate the existence of the price discount, a message that the price discount of 281,600 won or 138,600 won is applied to the operation of the price discount presentation is 138,000 
won for 1 year music ticket and 143,000 won for earphone. However, in the non-price discount video, the phrase about additional benefits for price discount was deleted.

\section{Results}

Two-way MANOVA analysis of T-commerce's scarcity message, self-monitoring, two independent variables, dependent promotional attitudes, and purchase intentions.

As a result of MANOVA analysis, two independent variables, the scarcity message and the main effect on self-monitoring, were Wilks' Lambda value of $\mathrm{F}=27.91$, which was significant at $99 \%$. However, the self-monitoring level was found to have no significant difference at $F=1.39(p>.01)$. The interaction effect on the two independent variables was Wilks' Lambda value at $\mathrm{F}=70.36$, which was significant at $99 \%$.

As a result of detailed ex post ANOVA analysis, first, the main effect on the scarcity message is that there are no significant differences in the promotion attitude $(\mathrm{F}=0.08, \mathrm{p}>.01)$ and purchase intention $(\mathrm{F}=2.78, \mathrm{p}>$.01). Appeared. However, self-monitoring showed significant differences in promotion attitude $(\mathrm{F}=49.99, \mathrm{p}<.01)$ and purchase intention $(\mathrm{F}=17.96, \mathrm{p}<.01)$. The interaction effect of independent variables on scarcity message and self-monitoring also showed statistically significant differences in both the promotion attitude $(\mathrm{F}=43.41 \mathrm{p}<.01)$ and purchase intention $(\mathrm{F}=1274.24, \mathrm{p}<.01)$. The MANOVA and ANOVA results between the two independent and dependent variables are shown in Table 1.

Table1 Research of MANOVA \& ANOVA

\begin{tabular}{lllll}
\hline Main Effect & $\begin{array}{l}\text { MANOVA } \\
\text { Wilks' Lambda(F) }\end{array}$ & $\boldsymbol{d f}$ & Attitude SP & $\begin{array}{l}\text { ANOVA } \\
\text { Purchase Intention }\end{array}$ \\
\hline A: Scarcity & $.98(1.39)$ & 2 & 0.08 & 2.78 \\
B: Self-Monitoring & $.72\left(27.91^{* *}\right)$ & 2 & $49.99^{* *}$ & $17.96^{* *}$ \\
AxB & $.51\left(70.36^{* *}\right)$ & 2 & $43.41^{* *}$ & $127.24^{* *}$
\end{tabular}

Note: ${ }^{*} \mathrm{p}<.05,{ }^{* *} \mathrm{p}<.01$

The difference between independent and dependent variables through post hoc ANOVA analysis is as follows. By examining the results of the main effects and interaction effects for each variable, the hypotheses were tested as follows.

Hypothesis 1 predicted that consumers with high levels of self-monitoring will have a more positive attitude toward sales promotions using limited-quantity messages than toward those using limited-time messages. As a result of the study, the promotional attitude was positive for the quantity-limited message $(M=5.00, S D=0.97)$ compared to the time-limited message $(M=3.98, S D=0.77)$. Therefore, Hypothesis 1 was supported.

Hypothesis 2 predicted that consumers with high levels of self-monitoring will have more positive purchase intentions when limited-quantity messages are used than when limited-time messages are employed. As a result of the hypothesis verification, the intention of purchase was higher than the quantity limit message $(M=5.82, S D=0.97)$ compared to the time limit message $(M=3.86$ and $S D=0.86)$. Hypothesis 2 was also supported.

Hypothesis 3 predicted that consumers with low levels of self-monitoring will have a more positive attitude toward sales promotions using limited-time messages than toward those using limited-quantity messages. As a result of hypothesis verification, the promotion attitude of the hypothesis verification result was positive compared to the time limit message $(M=3.91, S D=0.92)$ and the quantity limit message $(\mathrm{M}=2.97 ; \mathrm{SD}=1.01)$. Hypothesis 3 was thus supported.

Hypothesis 4 predicted that consumers with low levels of self-monitoring will have more positive purchase intentions when limited-time messages are used than when limited-quantity messages are employed. As a result of hypothesis verification, the intent of purchase was positive compared to the timelimited message $(M=4.93 ; S D=0.78)$ for the quantity-limited message $(M=3.48, S D=1.12)$. Hypothesis 4 was also supported.

Hypothesis 5 predicted that limited-quantity messages will have a greater effect on consumer attitudes toward sales promotions and purchase intentions compared to limited-time messages. No statistically significant difference was seen as a result of hypothesis testing between the promotional attitude $(M=4.06, S D=1.41)$ of quantitative messages and the promotional attitude of time-limited messages $(M=3.95$ and $S D=0.83)$. In addition, there was no statistically significant difference between the intention of purchasing a quantity-limited message $(\mathrm{M}=4.73, \mathrm{SD}=1.56)$ and the intention of purchasing a time-limited message $(M=4.71, S D=0.97)$. Five was dismissed. $<$ Figure $1>$ shows the results of the 
interaction effect between the independent variable and the dependent variable.
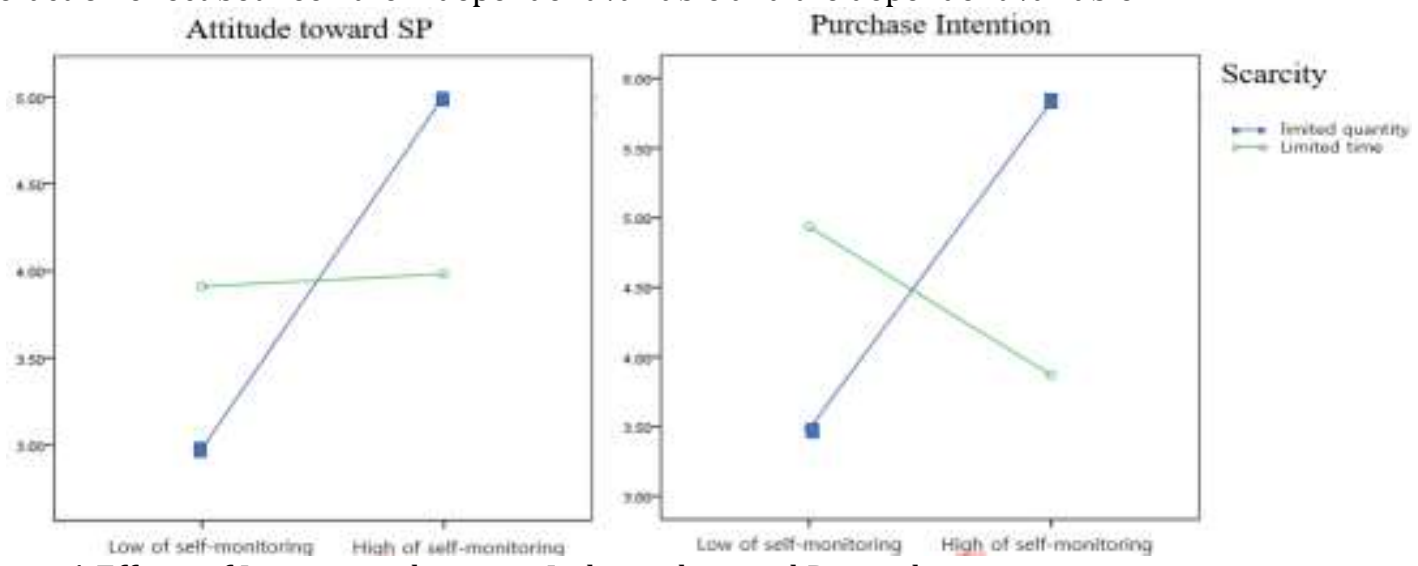

Figure 1 Effects of Interaction between Independent and Dependent

\section{Conclusions}

The purpose of this study was to empirically verify the effects of scarcity messages on sales promotions and purchase intentions of T-Commerce consumers, based on their self-monitoring levels. TCommerce is rapidly growing and utilizing various types of messages to promote sales. Among the scarcity messages, we examined limited-quantity messages and limited-time messages, along with the concept of self-monitoring.

The results of this study are as follows. First, consumers' attitudes toward sales promotions and purchase intentions in T-Commerce were found to be relatively positive with regard to limited-quantity and limited-time messages, with no major differences observed between the two types of messages. This is in sharp contrast to the results of prior studies, which have consistently shown that limited-quantity messages have a greater influence on consumers' purchase intentions than limited-time messages. However, most existing studies tended to neglect the value aspect of scarcity due to sales promotions, such as price discounts or bundled products. The scarcity value of a product is influenced by sales promotion messages that give additional value to the product, in addition to the other values of the product. The different effects of both types of scarcity messages suggest a need to re-examine the belief that limited-quantity messages have a more positive effect on consumers' purchase intentions than limited-time message, as reported in the prior studies.

Second, T-Commerce consumers with high levels of self-monitoring formed more positive attitudes toward sales promotions and has higher purchase intentions when limited-quantity messages were used, as compared to when limited-time messages were used. On the contrary, T-Commerce consumers with low levels of self-monitoring had a more positive attitude toward sales promotions and higher purchase intention when limited-time messages were used than when limited-quantity messages were employed. This means that the differential effect of scarcity messages is controlled by the self-monitoring levels of consumers. Consumers with low levels of self-monitoring are less sensitive to limited-quantity messages because they are strongly influenced by internal cues, such as their internal situations, attitude, aptitude, etc., and therefore rely more on their own conclusions and accordingly control their behaviors.

Third, a more positive attitude toward promotions and higher purchase intentions with limitedquantity messages are demonstrated by consumers with high levels of self-monitoring, rather than those with low levels. On the other hand, more positive attitudes toward promotions and higher purchase intentions with limited-time messages are formed in consumers with low self-monitoring levels than those with high levels. This is explained by the following reasons. When it is emphasized to consumers that the availability of a product (or service) is limited, consumers with high self-monitoring levels value the product (or service) more and exhibit a desire to own the product, as compared to consumers with low self-monitoring levels. Consumers with low self-monitoring levels tend to focus on the main attributes of a product and determine the product's value more positively in time-limited situations.

This study is significant as it established and experimented with a message strategy that can improve the intrinsic value of a product or service by delivering scarcity messages, and expanded the findings of prior studies that emphasized the external aspects of products or services, such as price discounts and premiums. In addition, the present study's findings have high generalizability because the promotional effects of scarcity messages have been empirically identified through the internal control variable of selfmonitoring, which extends beyond the limits of the effectiveness of scarcity messages. If the present findings are used for promoting online product and service sales through scarcity messages, it will be 
necessary to promote the inner values of consumers. Further, it would be insufficient to only emphasize the scarcity of products, and necessary to respond to the market segment by considering consumers' motivational systems.

It is likely that the results of this study will be generalized as this study reproduced actual promotional situations in the T-Commerce sphere and performed experiments.

Most consumers use T-Commerce while watching TV in the comfort of their homes. Therefore, a limitation of this study is that it was conducted in artificial settings, and that the subjects may have participated in the experiments after considering the study purpose. Additionally, it is necessary to measure the personal and subjective situations associated with consumers' intrinsic tendencies and lifestyles while simultaneously considering the changes in the controlling effects.

\section{Acknowledgements}

Funding for this paper was provided by Namseoul University

\section{References}

[1] Brock TC. Implications of commodity theory for value change. New York: Acadeic Press, 243; 1968.

[2] Stephen WA. The relationship between understanding of the nature of science and practice: The influence of teachers' beliefs about education, teaching and learning. International Journal of Science Education. 2006;28(8):919-944.

[3] Bozzolo AM, Brock TC. Unavailability effects on message processing: A theoretical analysis an empirical test. Basic and applied social psychology. 1992;13(1):93-101.

[4] Snyder M. Self-monitoring processes. Advances in Experimental Social Psychology. 1979;12:324-346.

[5] Park JE, Kim SW, Kim E, Kim SC. A Multi-criteria approach toward identifying determining factors of T-commerce adoption : Comparing T-commerce, TV home shopping, and online shopping. Korean Journal of Broadcasting and Telecommunication Studies. 2017;31(1):5-37.

[6] Lee D, Jeong H, Cho J, Jeong J, Moon J. Grocery shopping via T-Commerce in korea: new shopping channel adoption behavior based on prior e-commerce experience. International Food and Agribusiness Management Review. 2015;18(2):1-16.

[7] Bruno CG, Guilherme FL, Frank S. Conceptual models for Tcommerce in brazil. Proceeding of Workshop on Interactive Digital TV in Emergent Countries at EuroITV-Emergent Idtv. 2010;3(2):2227.

[8] Lynn M. Scarcity effects on value: Mediated by assumed expressiveness. Journal of Economics Psychology. 1989;10:257-274.

[9] Rice S, Keller D. Automation reliance under time pressure. Cognitive Technology. 2009;14(1):36-44.

[10] Verhallen TM, Henry SJ. Scarcity and preference: An experiment on unavailability and product evaluation. Journal of Economic Psychology. 1994;15:315-331.

[11] Jung JM, Kellaris J. J. Cross-national differences in progress to scarcity effects; The moderating roles of familiarity, uncertainty avoidance, and need for cognitive closure. Psychology and Marketing. 2004;21(9):739-759.

[12] Kelman HC. Attitude change as a function if response restriction. Human Relations. 1953;6:185-214.

[13] Snyder M. Self-monitoring of expressive behavior. Journal of Personality and Social Psychology. 1974;30(4):526-537.

[14] Mark T, Marc F. A study of visual puffery in fragrance advertising is tyenjessage message sent stronger than the actual scent?. European Journal of Marketing. 2011; 46(1/2):52-72.

[15] Aaker JL. The malleable self : The role of self-expression in persuasion. Journal of Marketing Research. 1999;36:45-57.

[16] Stayman DM, Kardes FR. Spontaneous inference processes in advertising: Effects of need for cognition and self-monitoring on inference generation and utilization. Journal of Consumer Psychology. 1992;1(2):125-142.

[17] Fromkin HL. A commodity theory analysis of consumer preference for scarce products. In Proceedings of the 79th Annual Convention of the America Psychological Association. 1971;6:521654. 